\title{
The Pancreas [Abridged]
}

\section{Dr K G Wormsley}

(University Department of Surgery, Royal Infirmary, Sheffield, S6 3DA)

\section{Tests of Pancreatic Function}

When disease of the pancreas is suspected on clinical grounds, the most satisfactory confirmation is often provided by demonstrating abnormalities of pancreatic exocrine function. At present, only tests involving direct or indirect (reflex) stimulation of the pancreas are sufficiently specific to discriminate between abnormal and normal function.

\section{Direct Stimulation of the Pancreas}

Tests involving direct stimulation of the pancreas are based on the assumption that pancreatic exocrine secretory capacity is being measured and that the pancreas is diseased if the secretory response is quantitatively reduced.

The most powerful tests for assessing the pancreatic capacity to secrete bicarbonate and enyzmes involve the direct stimulation of the pancreas with the parenterally administered small intestinal hormones secretin and pancreozymin. Since impairment of secretory capacity is being sought, it is worth emphasizing that near-maximal stimulation of the pancreas must be employed, in order to avoid confusion between an abnormally small response from an abnormal gland and a small response from a normal gland with a high threshold or low sensitivity to the hormones.

Bicarbonate secretion can be stimulated by secretin alone, given by intravenous injection or continuous intravenous infusion or in combination with pancreozymin, by infusion. Secretin injections (1-2 CU/ $\left.\mathbf{k g}^{1}\right)$ are easy to use, safe and reasonably cheap and discriminate well between normal and abnormal pancreatic function (Burton et al. 1960). However, secretin produces powerful contractions of the duodenum, which may lead to difficulty in the collection of duodenal juice and, since the pancreatic response to an injection of secretin is transient and continuously varying, very misleading measures of bicarbonate secretion

${ }^{1} \mathrm{CU}$, clinical units of Stockholm material may result. Secretin infusions (2 CU/kg-hour) elicit high levels of bicarbonate output, which provide absolute discrimination between normal and abnormal pancreatic function and have the advantage of producing steady rates of secretion into the duodenum, so that problems with aspiration can be avoided (Wormsley 1968).

Bicarbonate secretory capacity is best expressed in terms of output. The distribution of normal bicarbonate outputs is very skew (Fig 1) with a sharp cut-off at the lower end of the normal range, so that subjects with normal pancreatic function generally secrete more than $15 \mathrm{mEq}$ in 30 minutes, if adequately stimulated. In this connexion, it must be emphasized that it is essential to tailor each test to the subject being investigated, in order to obtain interpretable results. It follows that whenever a bicarbonate response is less than normal, it is necessary to carry out a further study, using a larger dose of secretin, to confirm that bicarbonate secretion is indeed impaired.

In earlier reports, bicarbonate secretory capacity was considered to be impaired if the 'maximal concentration of bicarbonate' of the

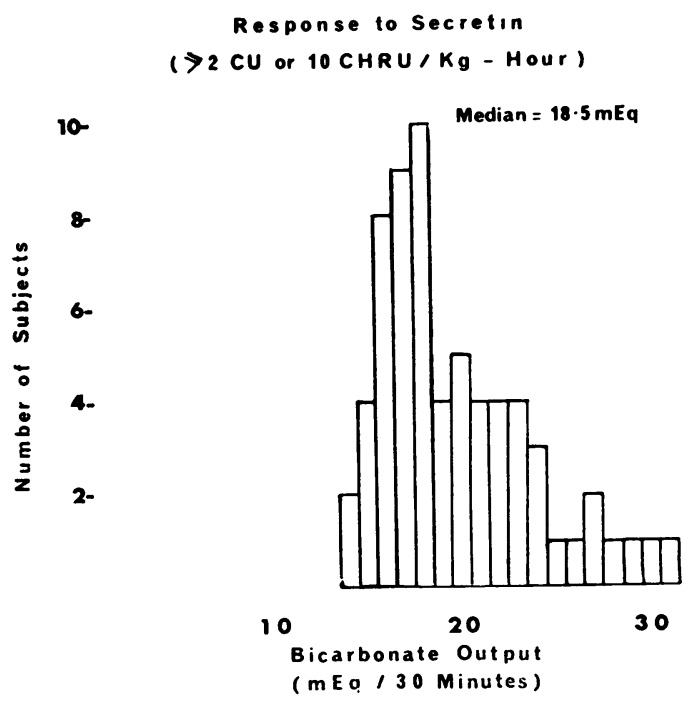

Fig 1 Bicarbonate outputs in response to secretin infusions in slibjects with normal pancreatic function. $C U$, clinical units of Stockholm material. CHRU, Crick, Harper, Raper units of Stockholm pancreozymin 


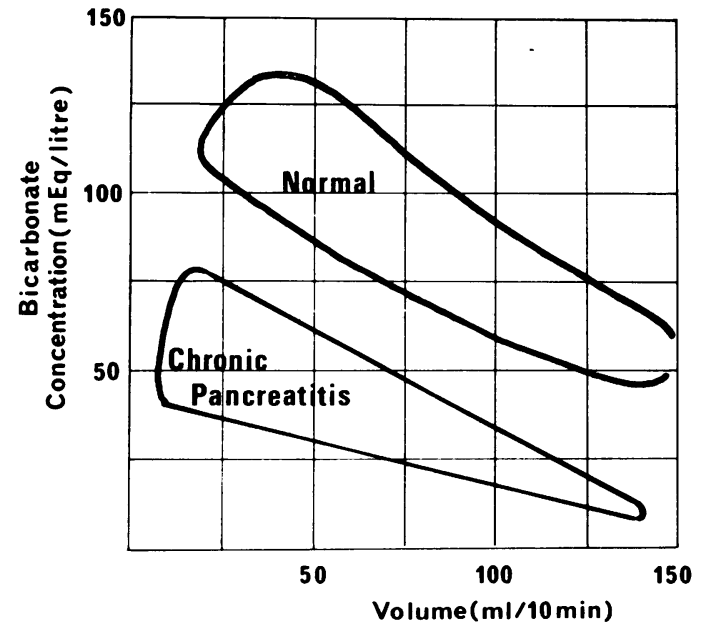

Fig 2 Relationship of bicarbonate concentration of duodenal contents to rate of secretion in response to intravenous infusions of secretin alone

duodenal aspirate during a test was low. While it is true that high $(>100 \mathrm{mEq} / \mathrm{l})$ concentrations of bicarbonate in the duodenal aspirate denote normal bicarbonate secretory capacity, low maximal bicarbonate concentrations cannot be used to differentiate normal from abnormal, since subjects with normal pancreatic function secrete juice with low maximal bicarbonate concentration if the rate of secretion is high. The bicarbonate output (that is, the product of concentration of bicarbonate and rate of secretion) of these normal subjects is quite normal, while the output of bicarbonate is low in patients with pancreatic insufficiency, because both concentration of bicarbonate and rate of secretion are low. Bicarbonate concentration must therefore always be assessed in conjunction with secretory rate (Fig 2).

Enzyme secretory capacity should always be studied in addition to, and not instead of, bicarbonate secretion, since the separation between normal and abnormal is not as clear cut as with bicarbonate. However, values of enzyme output corroborate the information derived from the measurement of bicarbonate secretion and also provide the basis for replacement therapy, by quantitating the degree of impairment of enzyme secretion.

Enzyme secretion can be stimulated by intravenous injections or infusions of pancreozymin alone or by combined infusion of secretin and pancreozymin. Pancreozymin injections (2-3 $\mathrm{CHRU} / \mathrm{kg}^{1}$ ) provide a moderately good degree of discrimination between normal and abnormal pancreatic function but produce an unsatis-

${ }^{1}$ Crick, Harper, Raper units of Stockholm pancreozymin factorily high proportion of side-effects. Infusions of pancreozymin alone are very weak stimulants of secretion of electrolytes and water from the pancreas and therefore give no information about bicarbonate secretory capacity. A combined infusion of a low dose of secretin $(0.25-0.5 \mathrm{CU} / \mathrm{kg}$ hour) together with a large dose of pancreozymin (16 CHRU/kg-hour) satisfactorily stimulates both enzyme and bicarbonate secretion and affords excellent separation of normal from abnormal pancreatic function (Fig 3) while entirely devoid of side-effects (Wormsley 1969). However, occasional subjects respond to the infusion of the combined hormones with a pattern of normal enzyme secretion and abnormally low bicarbonate output, due either to low potency of one of the hormones or to a high hormonal threshold, particularly in patients who have just recovered from acute pancreatitis. When this type of anomalous pattern is encountered, it is necessary to repeat the test, using a high dose rate infusion of secretin alone ( $2 \mathrm{CU} / \mathrm{kg}$-hour).

\section{Reflex Stimulation of the Pancreas}

Tests in this group are based on the assumption that the 'reflex' neurohumoral response to stimulants within the lumen of the alimentary tract can distinguish between a normally and abnormally functioning pancreatic target organ.

The standard technique until recently has involved the administration of a liquid meal (Lundh) consisting of protein, carbohydrate and fat (Worning \& Müllertz 1966). After ingestion, the duodenal contents are sampled and the enzyme concentrations measured and it is assumed that the concentration of enzymes reflects the enzyme secretory capacity of the pancreas. It is clear that the concentration of enzymes in random samples of duodenal contents depends on many factors other than pancreatic enzyme secretory capacity and, for this reason, quantitative recovery of the duodenal contents following small intestinal stimulation with acid or amino acids has been studied recently. It has been shown that normal subjects secrete as much bicarbonate and enzymes in response to intestinal acidification as to large doses of exogenous hormones. However, abnormal results (secondary pancreatic dysfunction) have been found in patients with small intestinal disease such as the coeliac syndrome, whose pancreatic response to direct stimulation is normal, emphasizing that tests involving 'reflex' stimulation of the pancreas are primarily tests of small intestinal, rather than pancreatic, function.

In summary, tests of 'reflex' secretory capacity are complementary to, but cannot be used instead of, tests involving direct stimulation of the pancreas, since the 'reflex' tests provide 

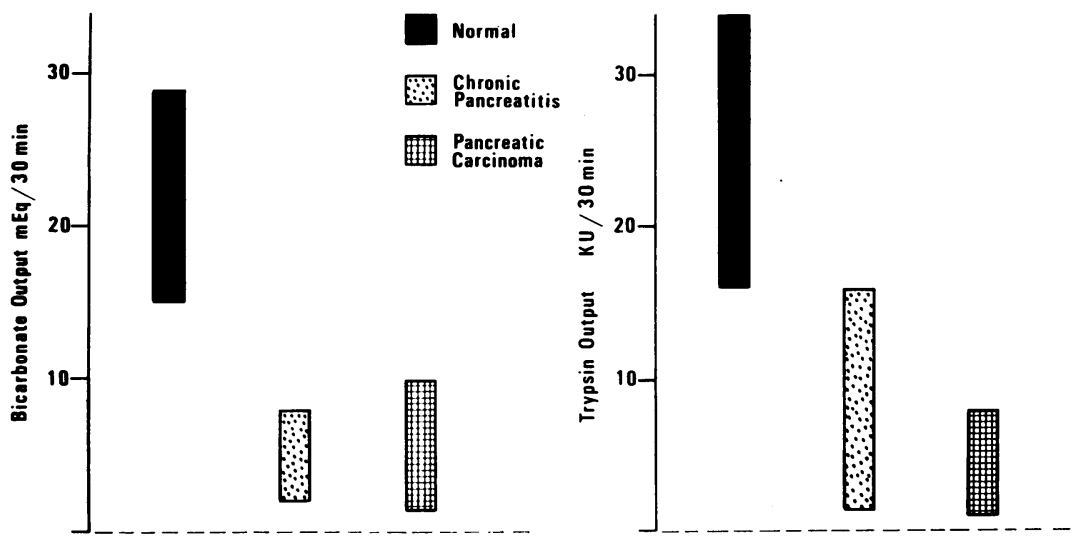

Fig 3 Bicarbonate and enzyme outputs in response to combined secretin $(0 \cdot 25 \mathrm{CU} / \mathrm{kg}$ hour) and pconcreozymin (16 CHRU/kg-hour) infusion. Doses refer to Stockholm hormones

information about the 'physiological' capacity of the pancreas to respond and do not necessarily measure total exocrine secretory capacity.

\section{Therapeutic-diagnostic Test}

It is sometimes not possible to intubate patients with suspected pancreatic steatorrhœa, due to a hyperactive gag reflex or to respiratory disease. Under these circumstances, it is possible to use a test which is diagnostically less satisfactory than tests involving intubation, but which appears to be specific within limits and which is also a guide to treatment. The test depends on the dramatic clinical and biochemical improvement in the steatorrhœa during administration of pancreatic replacement therapy, provided sufficient

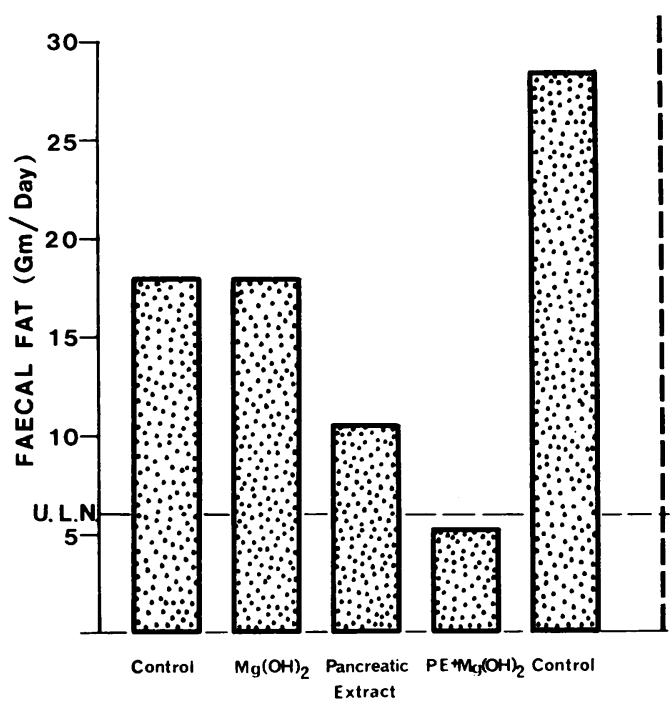

Fig 4 Facal fat excretion in patient with chronic pancreatitis during five-day periods without treatment and receiving antacids alone, pancreatic extract alone, combined antacids and pancreatic extract and no treatment, respectively antacid is given to prevent the rapid and irreversible destruction of the pancreatic enzymes in the stomach. A five-day control period, using standard balance techniques, is followed by five days with pancreatic extract, administered in powder form with each meal, together with antacid before, during and after the meal. Sufficient antacid to buffer any possible secretion of acid is required and if the gastric secretory capacity is not known, enough antacid to buffer at least $30 \mathrm{mEq}$ in 30 minutes should be provided. It is important to choose an antacid which keeps the intraluminal $\mathrm{pH}$ of the stomach high and which counteracts the constipation produced by effective replacement therapy, so that a combination of magnesium hydroxide or carbonate and sodium bicarbonate is usually most satisfactory. The results of replacement therapy in patients with pancreatic exocrine insufficiency is complete reversion to normal of the fæcal fat (Fig 4) and remarkable clinical improvement.

\section{Conclusion}

The exocrine secretory capacity of the pancreas is best studied by intubating the duodenum and subjecting the pancreas to direct stimulation with secretin and pancreozymin, preferably in the form of continuous intravenous infusion. This type of test is safe and provides excellent discrimination between normal and abnormal pancreatic function.

Acknowledgments: Grants from the Cystic Fibrosis Research Trust and from the Joint Committee on Cancer Research, University of Sheffield, are gratefully acknowledged.

REFERENCES

Burton P, Evans D G, Harper A A, Howat H T, Oleeshy S, Scott J E \& Varley H (1960) Gut 1, 111

Wormsley K G

(1968) Gastroenterology 54, 197

(1969) Scand. J. Gastroenterology 4, 623

Worning $\mathbf{H}$ \& Müllertz $S$

(1965) Scand. J. Gastroenterology 1, 268 